\title{
Portuguesismos léxicos de origen árabe en el contexto comunicativo atlántico
}

\author{
Lexical borrowings from Portuguese as Arab loanwords in the \\ Atlantic communicative context
}

\author{
Ana Ruth Vidal-Luengo y $M^{a}$ Teresa Cáceres-Lorenzo \\ Instituto Universitario de Análisis y Aplicaciones Textuales (IATEXT), Universidad de Las Palmas de \\ Gran Canaria, España. Correos electrónicos: anaruth.vidal@ulpgc.es; mteresa.caceres@ulpgc.es
}

La difusión del vocabulario románico influido por el árabe en el espacio atlántico constituye un capítulo de la expansión de la lengua española no suficientemente explorado, cuyo estudio contribuye a una reconstrucción más completa de esta influencia lingüístico-cultural. En este ámbito, el portugués y el español inauguraron una vertiente cultural atlántica en la que el léxico canario participa del legado árabe a través de ambas lenguas. El presente trabajo analiza cuantitativa y cualitativamente los portuguesismos léxicos del canario como posibles préstamos del árabe en diferentes corpus de esta variedad lingüística. Los resultados obtenidos nos indican que existen 47 portuguesismos canarios de origen árabe asociados a determinados tipos de préstamos, áreas léxicas y categorías gramaticales, y con una desigual presencia en América. Con estos datos se contribuye, desde el léxico dialectal, a la identificación de los arabismos en un contexto comunicativo atlántico.

Palabras clave: préstamos léxicos, español de Canarias, español de América, arabismos, portuguesismos

This work includes the Atlantic dimension as a part of the identity of Spanish language and an important chapter in the reconstruction of Romanic lexicon influenced by Arabic in the Spanish language expansion. In this area, Portuguese and Spanish opened an Atlantic cultural offshoot and the Canarian lexicon shared the Arab legacy through both languages. The objective of this research is the quantitative and qualitative analysis of Portuguese loanwords in Canarian Spanish, as possible borrowings from Arabic language in different corpora. The results of this analysis show 47 Portuguese loanwords in Canarian dialect, possibly of Arabic origin, related to particular types of borrowing, grammatical categories and lexical areas, with different presence throughout Hispanic America. These facts contribute to the identification of Arab loanwords in dialectal lexicon and its meaning in an Atlantic communicative context.

Key Words: lexical borrowings, Canarian Spanish, Spanish language in the Americas, Arab loanwords, Portuguese loanwords 


\section{INTRODUCCIÓN}

El examen del léxico dialectal del español atlántico proporciona indicios de la presencia de voces propias del occidente peninsular como parte de su vocabulario regional y diferencial (Frago García 2004; Morala Rodríguez y Le Men Loyer 2007; Medina López 2013). Estos occidentalismos léxicos provienen de Andalucía, de hablantes de otras provincias españolas que intervinieron en la expansión atlántica del español, pero también de los mismos portugueses (Buesa Oliver 1990; Corbella Díaz y Medina López 1996). Conquistadores, colonizadores y repobladores procedentes del territorio ibérico (portugueses y españoles) trasladan con un vocabulario común su visión del mundo y experiencias históricas a las nuevas tierras atlánticas, primero en la zona meridional peninsular, más tarde en las islas atlánticas y, posteriormente, en América (Lüdtke 2014).

Hasta la actualidad, en el panorama bibliográfico de estas variedades lingüísticas se ha insistido mucho en las relaciones entre las variedades románicas (Llorente Maldonado 1987; Ariza Viguera 1995), pero aún queda mucho por investigar en la vinculación del vocabulario románico influido por la lengua árabe, en el período de expansión de la lengua española en el espacio atlántico (Colón 2002, Fasla Fernández y Concepción 2000, Fasla Fernández 2007-2008, 2010; Corriente 2008a). Tales vínculos e influencias atañen a las disciplinas filológicas románica y árabe, y aúnan diversos elementos de interferencia cultural, entre ellos, los préstamos léxicos del árabe a las lenguas románicas, que se extienden más allá de los límites europeos y mediterráneos.

El estudio del léxico dialectal del español atlántico, por su relación con el aspecto cultural de la comunidad que lo utiliza, puede contribuir al reconocimiento de los orígenes interculturales de la cultura ibérica. La característica del español atlántico de conservar en su léxico sincrónico, voces ya olvidadas en otras regiones, y su desarrollo a través de los procesos de adopción, adaptación y la creación de formas lingüísticas posibilita esta indagación (Alvar 1996; Cáceres-Lorenzo 2007; Morgenthaler García 2008).

En este contexto, nuestra investigación se centrará en el canario ${ }^{1}$ como modalidad lingüística del español, que posee un buen número de corpus lexicográficos sincrónicos actualizados con criterios metodológicos unificados y científicos (García Mouton 2009). Estos materiales son el resultado de una renovación lexicográfica dialectal en la lengua española en Canarias, consecuencia de los atlas lingüísticos (Haensch 1997; Ávila 2003-2004; García Mouton et al. 2012), y ofrecen a los investigadores un material apto para convertirse en nuestro estudio de caso. El canario se caracteriza por conservar un gran número de portuguesismos léxicos que nos permite aglutinar referencias y consideraciones diferenciales propias, junto a lusismos comunes a

\footnotetext{
Dicha variedad lingüística se habla en las Islas Canarias (España), archipiélago a $150 \mathrm{~km}$. de África en el Trópico de Cáncer. Este territorio fragmentado lo conforman las islas de El Hierro, Fuerteventura, Gran Canaria, La Gomera, La Palma, Lanzarote y Tenerife, que tuvieron distinta funcionalidad en la expansión de portugueses y castellanos. Su localización estratégica en el Atlántico, como puerto en el camino a las Indias, y la bondad de su clima propiciaron el cultivo de la caña de azúcar, antes de implantarse en el Caribe americano. Al mismo tiempo, el presunto aislamiento de las islas con respecto a la Península que representan los $1.050 \mathrm{~km}$. de distancia, implica un alto grado de conservadurismo léxico. Desde el siglo XVI sirvió de puerto entre España y América, por lo que al rasgo conservador se le une la concomitancia léxica con ambas orillas peninsulares y americanas, fruto del contacto portuario continuo durante siglos.
} 
otras zonas atlánticas (Fernández-Sevilla 1975; Buesa Oliver 1990; Corbella Díaz y Medina López 1996).

En este trabajo, entendemos por portuguesismo léxico en las hablas canarias, el vocablo al que la lexicografía canaria le adjudica un étimo portugués, después de un análisis contrastado. También, hacemos nuestras las conclusiones de otros investigadores (Alvar 1959, Pérez Vidal 1991, Corbella Díaz y Medina López 1996; Corrales Zumbado y Corbella Díaz 2012; Morera Pérez 2009; Medina López 2013, Cáceres-Lorenzo 2015b) quienes concluyen que un portuguesismo es un término que llega a Canarias proveniente de Portugal peninsular e insular de manera directa o indirecta (a través de los mismos portugueses u otra comunidad de hablantes del occidente peninsular).

La conservación de voces lusas es una característica del español de Canarias. De hecho, Cáceres-Lorenzo (2015a: 189) contabiliza 1.507 portuguesismos en el léxico dialectal sincrónico, de los que el $68 \%$ son exclusivos de Canarias, y el resto son comunes a distintas regiones del territorio atlántico y peninsular. A este grupo de lusismos se unen las voces de procedencia occidental y andaluza (Alvar 1996). Un análisis de estos portuguesismos de las hablas atlánticas a la luz de las conclusiones de Steiger (1991); Corominas y Pascual (DCECH); Kiesler (KVWAI), Corriente (DAI, DAAL), especialmente en las áreas geográficas del español atlántico (Garulo Muñoz 1983; Corriente 2000, 2011, 2012) y del portugués (Corriente 1996, 2013; Alves 2013) hacen factible que nos planteemos lo siguiente: ¿cuántos portuguesismos del léxico dialectal pudieran ser préstamos del árabe?; ¿qué áreas léxicas aparecen representadas en este lexicón?

El objetivo general de esta investigación es verificar la posible existencia de un lexicón común a este espacio atlántico, y fruto del contacto entre grupos humanos. Este vocabulario pervive en el léxico dialectal, y en esta ocasión, nos centraremos en aquellas voces que la lexicografía en Canarias ha considerado portuguesismo léxico.

La elaboración de dicho lexicón nos permitirá cuantificar los términos seleccionados según el criterio anterior, y describir las áreas léxicas a las que pertenecen. Al mismo tiempo, con el fin de concretar su presencia atlántica, también hemos indagado sobre su potencial presencia en el español americano (Narbona Jiménez et al. 2011; López Serena 2013).

La hipótesis de partida es que Canarias recoge diferentes variedades del español (noroeste peninsular, Extremadura, Andalucía) a las que se suma la contribución directa o indirecta del portugués, por lo que el español insular se configura como un lugar de encuentro intercultural desde finales del s. XV (Llorente Maldonado 1987; Ariza Viguera 1995; Corrales Zumbado y Corbella Díaz 2012; Morera Pérez 2009; Medina López 2013).

El referido vocabulario común en la Macaronesia incluye los portuguesismos en diferentes áreas léxicas (p. ej., agricultura, ganadería y pesca, industria azucarera y de la seda, construcción, además de aspectos físicos, psíquicos y de la conducta), según los estudios de Pérez Vidal (1991), Corbella Díaz (1994), Herrera del Castillo (1996), Corrales Zumbado (2000). Estas áreas vitales para los repobladores de la Macaronesia y de América estaban influidas por el legado cultural andalusí, como se ha demostrado en los estudios sobre el origen árabe de la terminología especializada de la caña de azúcar (Nunes Nunes 2003, Corrales Zumbado et al. 2015) o de la seda (Serrano-Niza 2007). Por lo tanto, es factible encontrar aportaciones léxicas 
lusas de origen árabe en el español atlántico. En esta línea, Corriente (2012: 213) ha localizado 44 lusismos canarios de origen árabe, y Vidal-Luengo y Cáceres-Lorenzo (2014) han cuantificado 256 arabismos en distintos corpus dialectales sincrónicos sobre Canarias, incluyendo derivados y variantes, de los cuales 101 fueron descritos como portuguesismos por los distintos corpus de la lexicografía canaria.

La novedad de este trabajo radica en aunar los datos aportados por romanistas y arabistas para el español atlántico con la muestra de una parcela de estas interrelaciones léxicas que se manifiestan en los portuguesismos del canario. Asimismo el estudio caracteriza este acervo léxico reconociendo un nuevo parámetro que influye en su expansión en esta área geográfica.

\section{El pRÉSTAMO ÁRABE EN EL VOCABULARIO ROMÁNTICO}

La reconstrucción de un vocabulario románico de influencia árabe nos remite al concepto de la Romania Arabica, lo que implica considerar, para comprender los objetivos de esta investigación, la existencia de un espacio de amplio contacto lingüístico y cultural árabe-romance así designado en primer lugar por romanistas del ámbito centroeuropeo (Corriente 2008a: 10; cfr. Lüdtke 1996; Gessglen 1996), y posteriormente, introducido entre especialistas españoles para ilustrar especialmente su vertiente literaria (Galmés de Fuentes 1999-2000). Recientemente ha sido retomado para situar diversos elementos de confluencia hasta tiempos contemporáneos, faceta explorada en el ámbito lusohablante por Maranhão (2012).

En la dimensión lingüística de este espacio comunicativo románico y árabe del territorio peninsular destacan los arabismos léxicos como préstamos en las lenguas románicas del territorio peninsular, ya que dejan huellas más claras que otros elementos lingüísticos, como los gramaticales. En este sentido adoptamos la definición de préstamo léxico como "una palabra que en algún punto ha llegado a una lengua transferida de otra lengua" (Haspelmath 2008: 58).

En la escala de adoptabilidad (scale of adoptability), así denominada por Haugen (1950: 224) o jerarquía de disposición al préstamo (hierachy of borrowability) los nombres ocupan los primeros lugares por ser elementos de fácil inserción, seguidos de verbos y adjetivos (Dworkin 2008: 111). En estas palabras o grupos se hacen patentes las huellas de la interferencia lingüística árabe-románica, bien por ser préstamos directos del árabe con diferente grado de evolución léxica, o bien por incluir elementos fonéticos, léxicos o semánticos derivados de tal interrelación lingüística. Por tanto, excluimos la importación de morfemas dependientes, esquemas sintagmáticos y fraseología, cuya atestiguación es mucho más insegura, a pesar de haber sido explorada en Galmés de Fuentes (1996, cit. en Corriente 2008a: 77-79).

Existen muy diversas tipologías y clasificaciones de los préstamos entre lenguas atendiendo a causas extralingüísticas e intralingüísticas (Thomason y Kaufman 1988; Haspelmath 2008: 46-48 y 2009). El interés en estas últimas ha llevado a clasificaciones centradas en la morfología de los préstamos lingüísticos (Haugen 1950; Kiesler 1993), que no han sido puestas en suficiente correlación con el proceso de contacto e interferencia entre lenguas, y por lo tanto explican más cómo se produce esta dinámica, y no tanto sus causas. En el caso que nos ocupa, la interrelación léxica entre el árabe andalusí y las lenguas iberorromances ha derivado en un componente 
patrimonial significativo, fruto de diferentes fases y circunstancias históricas cambiantes durante un largo espectro temporal, que se prolonga en su periplo al otro lado del Atlántico como subcomponente léxico específico.

La tipología presentada por Kiesler (1993), siguiendo a Haugen (1950), se centra en los procesos de importación -los llamados préstamos directos- y sustitución, que incluyen los llamados hibridos, sean traducciones totales o parciales, calcos, préstamos semánticos o creaciones prestadas. A propósito de los arabismos en lenguas iberorromances, Corriente (2008a: 79-81) establece tres tipos de préstamos acorde al origen etimológico, de los cuales uno podemos identificar con procesos de importación (préstamos directos en el árabe andalusí, o en su defecto, con referencia al árabe clásico), y los otros dos surgirían en procesos de sustitución (romandalusismos o préstamos del romance andalusí o meridional y voces híbridas, que incluyen elementos del árabe andalusí y del romance), pues en estos se observan fenómenos de metanálisis, semitraducción y calco que revelan estrategias de absorción lingüística en diferentes fases de superación del bilingüismo, apropiación lingüística y sustitución.

En este artículo, prestaremos especial atención a este último grupo de voces híbridas, que se enmarcan posiblemente en situaciones de bilingüismo, progresando hacia un deslizamiento lingüístico, y que suponen un mayor grado de compromiso intercultural y denotan la creación de entidades totalmente nuevas. Es posible que estas voces sean más frecuentes en una variedad del español como el canario, dado que se forma hacia el final de este largo proceso de interferencia árabe-romance.

Por lo tanto, haremos referencia a dos tipos de fenómenos derivados de la interacción entre el árabe andalusí y las lenguas ibéricas romances: arabismos por importación del árabe andalusí (o que sólo se pueden relacionar con términos árabes clásicos), y arabismos por sustitución parcial o total, que incluyen influencias de sustrato (romandalusismos) o adstrato (arabismos con afijación romance, traducciones parciales, calcos, derivaciones intrarromances y préstamos semánticos).

Con frecuencia, aparecen arabismos importados del andalusí con una correspondencia al árabe clásico como mera referencia, sin que esto signifique necesariamente una relación genética (DAAL: xiv). Existe un consenso generalizado en que la mayoría de los préstamos se producen en contextos lingüísticos orales, por lo que no hay razón alguna para excluir de esta norma a los préstamos del árabe en las lenguas romances peninsulares. No obstante, siempre se pueden dar préstamos a través de la lengua escrita (Haugen 1950: 223), como efectivamente se produjeron en el caso del árabe, aunque en menor escala (Dworkin 2008: 113-114), o simplemente concomitancias entre este registro formal del árabe y las variantes coloquiales.

Nuestra atención se centrará en los casos de sustitución, que se dan en romandalusismos y voces híbridas. Los primeros son palabras con origen en el romance andalusí o meridional incorporadas al árabe andalusí. Estas influencias de sustrato perduraron durante el período de monolingüismo en al-Andalus y cuando volvieron al medio romance portaban ya elementos morfológicos o fonéticos significativos en su paso por el árabe, en un momento en el que había intercambiado el papel de lengua donante por receptora. Entre ellos se incluyen las denominaciones de Nova Realia para los cuales la lengua dominante puede haber presentado insuficiencia designativa (Cáceres-Lorenzo 2007). Versteegh (2001: 474) señala, a propósito de estas pervivencias, que pueden implicar un largo periodo de alternancia de código (code-switching) con diferentes grados de pérdida lingüística dentro de los hablantes. 
Muchos de los arabismos híbridos analizados exhiben una raíz árabe andalusí insertada con afijación o sufijación romance que se identifica como creación propia. En opinión de Haugen (1950: 220-222) estas sustituciones a la inversa no se originan en procesos de préstamo, sino que revelan una fusión íntima del material lingüístico prestado, ya que es productivo en la nueva lengua, en este caso, el portugués y el español y sus variantes. Esto es especialmente destacable en voces que han sufrido un desplazamiento semántico, debido a condicionantes diatópicos. Algunos autores han diferenciado las interferencias de sustrato y adstrato de los préstamos, ya que forman parte de un proceso de desplazamiento o cambio lingüístico (shift) (Thomason y Kaufman 1988), aunque en otras tipologías se explican en esos contextos de cambio como imposiciones inconscientes de los no nativos en la lengua receptora (Ross 1991, cit. en Haspelmath 2008: 46-47).

Es muy difícil saber si el proceso de derivación se dio ya en el árabe andalusí, tomando elementos del romance en época temprana, o más tarde en época mudéjar y morisca, o bien se debe a una derivación intrarromance, posterior a la adopción del arabismo (Corriente 2008a: 62-65). En este estudio sobre los arabismos del portugués en el español canario se incluyen este tipo de voces para verificar la continuidad del legado de la Romania Arabica como espacio comunicativo en una nueva fase creativa.

Por tanto, el parámetro del étimo o vinculación al árabe sirve para caracterizar el valor cultural del léxico y su papel en la difusión a través del Atlántico. En la dinámica de las lenguas en contacto, el préstamo directo o por importación indica mayor prestigio y desigualdad de la lengua donante sobre la receptora, como se ha indicado respecto al caso de interferencia árabe-románica peninsular (p. ej. Fasla Fernández 1998-99), mientras que la pervivencia de formas de sustitución parcial o total o híbridos indican periodos de bilingüismo, con alternancia de código y zonas de cambio, en las que hay mayor equilibrio y aportación mutua, constatada por una huella morfológica o léxica.

La presencia de préstamos del árabe en diferentes parcelas semánticas también puede indicar, en nuestra opinión, el grado de interrelación social y sincretismo cultural. Dado que las hablas canarias se sitúan como derivación del proceso de interferencia árabe-romance, es posible que haya cierta relevancia en los ámbitos personal, familiar, comunal o profesional. En este sentido tenemos en cuenta los estudios diacrónicos sobre áreas léxicas (García González 2007 y 2008: 277-281).

Todas estas condiciones explicarían la difusión de estas voces a través del Atlántico como seña de identidad de ambas orillas o indicador de una conciencia lingüistica, entendida esta como información extralingüística del uso del léxico (Martinell Grifé y Cruz Piñol 1996).

\section{DiSEÑO DE LA INVESTIGACIÓN Y DESCRIPCIÓN DE LOS CORPUS}

Con el fin de responder a las preguntas de investigación y alcanzar los objetivos descritos para este estudio, y con una metodología de naturaleza cuantitativa y cualitativa, hemos seguido los siguientes pasos:

$-1^{\text {a }}$ fase: elaboración de un corpus de portuguesismos según las principales fuentes lexicográficas dialectales del español de Canarias: Tesoro Lexicográfico del Español de Canarias (TLEC 1992), Diccionario Diferencial del Español de 
Canarias (DDEC 1996), Diccionario ejemplificado de canarismos (DEC 2009) y Diccionario Histórico del Español de Canarias (DHECan 2013). Los estudios que se han tenido en cuenta para la selección de vocablos de origen árabe son obras y estudios lexicográficos que consideran al árabe andalusí como fuente principal de préstamos del árabe en el ámbito iberorromance (Steiger 1991: 12; cfr. Corriente 2008a: 12, nota 7; y García González 2008: 258): Diccionario crítico y etimológico castellano e hispánico (DCECH), Kleines vergleichendes Wörterbuch der Arabismen im Iberoromanischen und Italienischen (KVWAI), Diccionario de arabismos y voces afines en iberorromance (DAI), Dictionary of Arabic and Allied Loanwords: Spanish, Portuguese, Catalan, Galician and Kindred Dialects (DAAL), para los arabismos del español, y Corriente (2013) para los del portugués. Asimismo se han revisado estudios sobre los arabismos presentes en las hablas andaluzas (Garulo Muñoz 1983) y en las canarias (Corriente 2000, 2011, 2012). En este proceso se han descartado las lexías que presentaban dudas para relacionarlas con una correspondencia en portugués y así establecer su condición de préstamos lusos con mayor seguridad.

$-2^{a}$ fase: confrontación con los datos obtenidos con los aportados por los estudios sobre arabismos, selección de términos más primarios, excluyendo derivaciones y variantes gráficas ${ }^{2}$, y clasificación en diferentes grupos según su etimología. Una vez concluida esta segunda fase, se decidió presentar los resultados en dos tablas independientes; por un lado, presentamos los portuguesismos acorde a los datos proporcionados por romanistas sobre el español de Canarias (fase 1) y por otro, las aportaciones hechas desde los estudios realizados desde una perspectiva áraberománica. Con este procedimiento se busca diferenciar los aportes de una disciplina y otra.

$-3^{\text {a }}$ fase: verificación de la presencia de estas voces en el español americano según el Diccionario de Americanismos (DA) y el Diccionario de la Real Academia Española (DRAE 2014).

\section{AnÁlisis de Resultados}

El desarrollo de las fases anteriores nos ha proporcionado los datos que aparecen en las Tablas 1 y 2. En éstas se ha recogido la información que es útil para caracterizar los portuguesismos de Canarias de procedencia árabe ${ }^{3}$.

De los 36 ejemplos que aparecen en la lexicografía canaria descritos en la Tabla 1, solamente 9 se han registrado en América, con desigual difusión. Tres de ellos tienen una distribución general por países de América continental e insular (bardino, tacho, zafado), y el resto aparecen en la zona del Caribe (cachaza 'espuma del guarapo' y

En los casos de variantes con aglutinación y deglutinación del artículo en árabe hemos incluido la voz más frecuente según los corpus lexicográficos canarios, como en los ejemplos de alfarroba, almajurada, labaza y tabefe, que presentan también las variantes farroba, majurada, alabaza y atabefe. Un caso distinto es alfonsiño, que parte hipotéticamente del bereber *arfos, y es metanalizado posteriormente en árabe andalusí.

3 Hemos seguido el sistema utilizado en DAAL tanto para la transliteración de vocablos del árabe clásico o árabe andalusí como para las abreviaturas. Las formas hipotéticas llevan asterisco * y las formas romances, sufijos y afijos van en mayúscula para su mejor diferenciación. Los cruces por coincidencia fónica o contaminaciones semánticas se señalan con el signo + . 
'desvergüenza', margullar, tacha) y en otras áreas, como tarrafa en Perú y Paraguay, y zafra en Uruguay y Cuba, en sus dos acepciones.

Tabla 1. Inventario de portuguesismos en corpus dialectales del español de Canarias

\begin{tabular}{|c|c|}
\hline $\begin{array}{l}\text { Lusismos del español de Canarias } \\
\text { (TLEC; DDEC; DEC, DHECan) }\end{array}$ & $\begin{array}{l}\text { Hipótesis etimológica } \\
\text { (DCECH; Garulo 1983; KVWAI; Corriente 2000, } \\
\text { DAI, DAAL, 2011, 2012, 2013) }\end{array}$ \\
\hline abicero 'vertiente umbría de un barranco' & and. *ṣáḥb azzád / ár. șāhib azzād \\
\hline $\begin{array}{l}\text { acevén, acebén 'tipo de gramínea } \\
\text { (Lolium perenne)' }\end{array}$ & and. zawán \\
\hline alfonsiño 'especie de pez de color rojo' & and. *alfúss \\
\hline albajar 'especie de tiburón' & and. kálb albáhr \\
\hline $\begin{array}{l}\text { albazul, albazur 'tabla que va de banda a banda del barco } \\
\text { de pesca' }\end{array}$ & híbr. and. *alwáșl+ÓN / ár. wașūl \\
\hline alfarroba 'fruto del algarrobo' & and. alxarrúba \\
\hline algeroz 'canal de tejado' & and. jarúz \\
\hline alhorra 'hongo o parásito del cereal' & and. *(šakíyyat $)$ alhúrr \\
\hline alicerce 'zanja para los cimientos' & and. alasás \\
\hline almajurada 'especie de hipérico (Hypericum canariense)' & híbr. and. almahfúra $+\dot{A} D A$ \\
\hline andoriña 'golondrina' & híbr. and. haddúra+ÍNA + rom. *arundína \\
\hline azucre 'azúcar' & and. assúkkar \\
\hline bardino 'referido a un animal, de color marrón oscuro' & híbr. and. bardí + lt. pardus ${ }^{4}$ \\
\hline cachaza 'espuma del guarapo’ & híbr. and. $x a ́ z z+\dot{A} \check{C} \check{C}$ \\
\hline cachaza 'desvergüenza, descaro' & híbr. and. $x a ́ z z+\dot{A} \check{C} \check{C}$ \\
\hline calaza 'pereza' & and. xaláṣ \\
\hline cotio 'variedad de higo' & and. qutí \\
\hline gilbarbera 'planta ornamental de frutos rojos' & híbr. ár. jilbāb+É YRA \\
\hline labaza 'hierba poligonácea (Rumex acetosa)' & romand. labbása $<$ 1t. lăpăthǐum \\
\hline lula 'especie de jibia' & 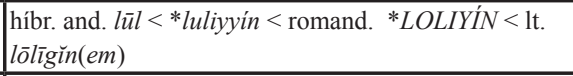 \\
\hline magarefo 'hombre desaliñado' & neo-ár. muqarrif + and. muxațif \\
\hline margullar 'acodar' & híbr. and. margál $+\dot{A} R$ \\
\hline margullar 'bucear, sumergir' & híbr. and. margál $+\dot{A} R$ \\
\hline mazaroca 'husada' & and. mas/súrqa / ma/ușrúqa \\
\hline mazaroca 'mazorca de maíz' & and. mas/șúrqa / ma/ușrúqa \\
\hline quelme 'especie de tiburón’ & and. kálb albáhr / ár. kalbu lbaḥr \\
\hline rabilero 'sinvergüenza, bribón' & híbr. and. rabáb+É $Y R O$ \\
\hline seifia 'mojarra (Diplodus vulgaris)' & and. sayfiyya \\
\hline tabefe 'suero' & and. tabix \\
\hline tacha 'paila grande para elaborar el azúcar' & and. țást \\
\hline $\begin{array}{l}\text { tacho 'caldero ancho para cocer el melado y dar el punto } \\
\text { de azúcar' }\end{array}$ & and. tást \\
\hline taramela 'pieza de madera para cerrar puertas y ventanas' & híbr. and. taráa $b+E \underline{E} \underline{L} A$ \\
\hline tarrafa'red de pesca' & and. atțarráha \\
\hline zafado 'descarado' & and. $s \grave{a} f(i) /$ and. $z \bar{a} h+\dot{A} D O$ \\
\hline zafra 'época de cosecha' & and. sáfra \\
\hline zafra 'cosecha de la caña de azúcar' & and. sáfra \\
\hline
\end{tabular}

$a ́ r$. árabe clásico; and.$=$ árabe andalusí; $b r .=$ bereber; hibr. = híbrido; $l t$. = latín; neo-ár = neo-árabe; rom. $=$ omance; romand.$=$ romance andalusí 
En los resultados de la tabla 2, los portuguesismos canarios que pueden considerarse como préstamos del árabe no aparecen registrados en América (DA, DRAE 2014). Se trata de recientes incorporaciones al inventario de arabismos realizadas por Corriente (2011 y 2012), quien probablemente centra su atención en vocablos exclusivos de las hablas canarias, entendidos como aquellos que no comparten difusión en otras zonas geográficas del español. Por tanto, tienen más probabilidad de ser préstamos directos del portugués y que sólo han pervivido en Canarias, a falta de un estudio diacrónico de su recorrido en su difusión en el espacio lusohablante.

Tabla 2. Glosario de lusismos de origen árabe según la lexicografía árabe-romance

\begin{tabular}{|c|c|}
\hline $\begin{array}{l}\text { Lusismos del español de Canarias } \\
\text { (DCECH; Garulo 1983; KVWAI; Corriente 2000, } \\
\text { DAI, DAAL, 2011, 2012, 2013) }\end{array}$ & $\begin{array}{l}\text { Hipótesis etimológica } \\
\text { (DCECH; Garulo 1983; KVWAI; Corriente 2000, } \\
\text { DAI, DAAL, 2011, 2012, 2013) }\end{array}$ \\
\hline anequin, 'tipo de tiburón (Prionace glauca)' & and. iklil \\
\hline atafullarse, 'atragantarse' & híbr. *A(D)+tahwil +ÁR \\
\hline bandonga, 'barriga' & híbr. and. baṭn+ÚUK/L/L \\
\hline chuchar, 'sorber' & híbr. romand. * $\check{C}^{\prime} U \check{C}+\check{A} R<$ lt. sugere + and. šús̆ \\
\hline chuchar, 'aprovecharse' & híbr. romand. $* \check{C} U \check{C}+\dot{A} R<$ 1t. sugere + and. šúš \\
\hline farrumaque, 'extravagancia, fanfarronería' & and. hirr úmmak \\
\hline forfolino, 'libra especiera' & and. fulfuli \\
\hline gorgomilo, 'garganta' & romand. GARGAMÉL > and. gargamil \\
\hline ruazo, 'tipo de mamífero marino' & and. arrawwás \\
\hline sumagre, 'zumaque (Rhus coriaria)' & and. summáq \\
\hline tomaria, 'ojalá' & and. atámm alláh \\
\hline
\end{tabular}

and. = árabe andalusí; hibr. $=$ híbrido; $l$. $=$ latín; romand.$=$ romance andalusí

Entre los arabismos de origen portugués presentes en las hablas canarias, los préstamos por sustitución o directos del árabe andalusí al portugués, que para el canario son indirectos, contabilizan un total de 28 voces, es decir, el 59,57\%. Las 19 formas que denominamos híbridas $(40,42 \%)$ incluyen tanto vocablos que en origen eran préstamos del romance andalusí al árabe andalusí (influencias de sustrato) como formas de esta lengua en combinación con prefijos o sufijos romances (influencias de adstrato respecto al árabe andalusí, y en época posterior, de sustrato respecto al romance, o derivación intrarromance de un arabismo), además de contaminaciones fónicas o cruces semánticos entre ambas lenguas. Los romandalusismos son un grupo poco representativo, significando 4 voces de las que 2 han sido documentadas en árabe andalusí (labaza, gorgomilo). En este sentido, consideramos que estos términos se pueden añadir al cómputo de voces híbridas, pues son pervivencias romances en un medio arabófono que implican la adaptación a modelos presentes en el árabe andalusí.

En las tablas anteriores se presentan arabismos portuguesismos de diferentes áreas léxicas. Los campos mejor representados son los de la cultura marinera (ictionimia, aparejos y técnicas de pesca, elementos de la embarcación: anequín, afonsiño, albajar, lula, quelme, ruazo, seifía, margullar 'sumergir', tarrafa, albazul) y de la ganadería y agricultura (abicero, alfarroba, alhorra, cotio, forfolino, margullar 
'acodar', mazaroca 'husada', mazaroca 'mazorca', tabefe, zafra 'época de cosecha'), con 10 ejemplos por área. Las voces relacionadas con la flora y fauna terrestre reúnen 7 ejemplos (acevén, almajurada, gilbarbera, labaza, sumagre, andoriña, bardino), al igual que los términos referentes a la descripción de características físicas o psíquicas y comportamiento humano (cachaza, calaza, magarefo, rabilero, zafado, farrumaque, chuchar 'aprovecharse'). A continuación el léxico de la industria azucarera, está representado con 5 ejemplos (azucre, cachaza 'espuma del guarapo', tacha, tacho, zafra, 'cosecha de la caña de azúcar'). Por último, destacamos un grupo de 4 voces relacionadas con partes del cuerpo y acciones fisiológicas (bandonga, gorgomilo, atafullarse, chuchar 'sorber'), ya que sólo restan dos áreas minoritarias relacionadas con la construcción (algeroz, alicerce, taramela), y expresiones (tomaría).

Estos resultados corroboran otras afirmaciones realizadas por Corrales Zumbado y Corbella Díaz (2012) respecto al léxico canario de origen portugués. A su vez, coinciden con el grueso de términos cuya hipótesis etimológica está apoyada por voces documentadas en árabe andalusí, que pertenecen a un período de importación lingüística directa del árabe, que según García González (2008: 280) se sitúa en la Baja Edad Media, con el contacto entre comunidades arabófonas y romances en la época de grandes conquistas y repliegue del dominio islámico.

Atendiendo a los resultados obtenidos en diferentes campos léxicos y respecto al parámetro del tipo de préstamo originario, por importación o sustitución, destacan 35 términos que aluden a flora, fauna, objetos y utensilios, seres y objetos tangibles, entre los cuales 24 tienen origen en palabras importadas del árabe andalusí, y 10 son voces híbridas, que aluden en su mayoría a especies de flora y fauna local mediante epítetos (p. ej. almajurada "perforada", andoriña "parlanchina", gilbarbera "manto bermejo") o a terminología técnica de la pesca, la agricultura y la industria azucarera. En los 19 vocablos originados por una hibridación encontramos 10 términos que aluden a realidades objetivas, frente a 9 que se relacionan con actitudes y comportamientos humanos.

Por otra parte, los campos léxicos relacionados con el ser humano, su fisiología y comportamiento reúnen 12 palabras $(25,53 \%)$, de las cuales 9 son de naturaleza híbrida. Destacan 5 términos alusivos a apreciaciones o valoraciones humanas (cachaza 'desvergüenza', magarefo, rabilero, zafado, chuchar 'aprovecharse') y, significativamente, 4 voces relativas al cuerpo (bandonga, gorgomilo, atafullarse, chuchar 'sorber') que en su totalidad son fruto de una hibridación árabe-romance.

Respecto a las categorías gramaticales, el lexicón descrito incluye 39 nombres, 4 adjetivos y sólo 3 verbos (atafullarse, margullar, chuchar), los dos últimos con desdoble semántico respecto al significado primitivo de los hipotéticos arabismos originales. Este dato coincide con las últimas investigaciones sobre la disposición al préstamo de las categorías gramaticales en 41 lenguas (Tadmor 2009: 61-63), que establecen una jerarquía en la que los adjetivos son ligeramente más dispuestos a ser préstamos que los verbos, aunque la situación de cada lengua difiere por causas históricas o estructurales. Los resultados aportados también son congruentes con las tendencias apreciadas en los adjetivos del español que son préstamos del árabe, entre las que se incluyen los términos de color (en este caso, bardino) y de características negativas (Dworkin 2008: 117-119) como magarefo, rabilero y zafado. Esta peyorización de los arabismos, según García González (2008: 281) ya estaba presente en el S. XIII y avanza durante toda la Baja Edad Media. 


\section{CONCLUSIONES}

En esta investigación realizada con los portuguesismos del canario, queda demostrado que el subcomponente léxico hispánico de origen árabe forma parte del espacio atlántico. Pero además, los datos obtenidos son indicadores lingüísticos de que estamos ante un vocabulario común, cotidiano y comunicativo, como demuestran los ejemplos que hacen referencia a voces expresivas y relacionadas con el comportamiento humano.

Las áreas léxicas con más ejemplos coinciden con la agricultura y flora, y la tecnología, y las emociones y valores o el cuerpo. Según los estudios comparativos realizados sobre la disposición al préstamo léxico (Tadmor 2009: 64-65) este vocabulario es más propenso al préstamo entre diferentes lenguas.

Los términos de origen andalusí localizados en los portuguesismos del español de Canarias corroboran que las causas más comunes de la importación directa de préstamos son el prestigio de la comunidad lingüística donante y la insuficiencia léxica en la lengua receptora. Es posible que, tratándose de términos a menudo técnicos, relacionados con oficios y labores en los que los árabes destacaron históricamente, su pervivencia y difusión atlántica indica en cierto modo la identificación con una tradición cultural. Esta identidad se puede conectar con diferentes hechos: los oficios de los desarraigados de su territorio de origen, por cuestiones religiosas o socioeconómicas, cristianos nuevos y moriscos que se dedicaron principalmente a tareas agrícolas y ganaderas o industrias artesanas, la convivencia entre gentes del mar en el Mediterráneo, Atlántico, y, en el caso de Portugal, también el Índico, lugares donde confluyen puntos de intersección árabe-romance (Corriente 1996: 6; Maranhão 2012: 175).

Pero esta idea se matiza con la presencia entre los portuguesismos canarios analizados de un considerable número de voces $(40,42 \%)$ que incluyen hibridaciones creativas en base a arabismos heredados o voces romandalusíes de sustrato, derivación semántica y derivaciones efectuadas en medio romance. Estas voces coinciden en un $25,53 \%$ con áreas léxicas que no responden a cuestiones de prestigio o insuficiencia léxica, sino a necesidad de matices expresivos menos objetivables (Dworkin 2008; García González 2007: 280-281).

Somos conscientes de que este trabajo realizado con corpus dialectales, localizados a través de diccionarios regionales del canario, tiene que ser completado con otros corpus en otras áreas lingüísticas del español atlántico. En muchos casos es probable que no se pueda datar la aparición de ciertas palabras que hemos incluido como híbridas en contexto bilingüe árabe-romance o en época posterior, bajo el influjo de sociolectos como el aljamiado-morisco. La detección y datación de los romandalusismos que deben ser las voces híbridas más antiguas, es también probablemente incompleta (Corriente 2008b). Por último, la selección de portuguesismos y arabismos en el canario sigue abierta, pues ulteriores investigaciones pueden desvelar nuevos vocablos producto de la interferencia árabe-románica presentes en el espacio atlántico (Fasla Fernández y Concepción 2000, Fasla Fernández 2010).

\section{OBRAS CITADAS}

Alvar, Manuel. 1959. El español hablado en Tenerife. Madrid: Consejo Superior de Investigaciones Científicas. Alvar, Manuel. 1996. "Canario". Manual de dialectología hispánica: el español de España. Manuel Alvar, ed. Ariel: 
Barcelona. 126-145.

Alves, Adalberto. 2013. Dicionário de Arabismos da língua portuguesa. Lisboa: INCM.

Ariza Viguera, Manuel. 1995. "Leonesismos y occidentalismos en las lenguas y dialectos de España". Philologia hispalensis 10: 77-88.

Ávila, Raúl. 2003-2004. “¿El fin de los diccionarios diferenciales?, ¿el principio de los diccionarios integrales?”. Revista de lexicografia 10, 7-20.

Buesa Oliver, Tomás. 1990. "Problemas para la identificación del andalucismo léxico en el español de América". Actas de las VII Jornadas de Andalucia y América. Sevilla: Junta de Andalucía. Vol. II. 269-282.

Cáceres-Lorenzo, M. Teresa. 2007. "Transculturización, adaptación, reajustes e influencias en el léxico de la época de los Austrias: interacciones en los zoónimos canarios". Neophilologus 91.3: 423- 437.

2015a. "Portuguesismos y occidentalismos léxicos en las hablas canarias. Aportaciones desde el léxico dialectal sincrónico". Homenaje a José Antonio Martínez. Ed. Serafina García. Oviedo: Universidad de Oviedo. 181-195. DOI: 10.13140/RG.2.1.2832.4008

2015b. "Elementos diferenciales en el español atlántico: andalucismos y occidentalismos léxicos en el canario". Revue Romane 47.2: 1-15.

Colón Domènech, Germà. 2002. "De arabismos interhispanos". Para la historia del léxico español. Vol. I. Eds. Albert Soler y Núria Mañé. Madrid: Arco Libros. 45-54.

Corbella Díaz, Dolores. 2012. "Lexicografía histórica de ámbito regional. Proyectos y resultados". Lexicografia hispánica del siglo XXI, nuevos proyectos y perspectivas: homenaje al profesor Cristóbal Corrales Zumbado. Madrid: Arco Libros. 191-210.

Corbella Díaz, Dolores y Javier Medina López. 1996. "El contacto del portugués y el español en Canarias: estado de la cuestión". Actas del Congreso Internacional luso-español de la lengua y cultura en la frontera: Cáceres, 1 al 3 de diciembre de 1994. Coord. Juan María Carrasco González y A. Viudas Camarasa. Cáceres: Universidad de Extremadura, Servicio de Publicaciones. Vol. I. 509-518.

Corrales Zumbado, Cristóbal. 2000. "Portuguesismos en los orígenes del español de Canarias". Homenaje a Alfonso Armas Ayala. Las Palmas de Gran Canaria: Cabildo Insular de Gran Canaria. Vol. I. 401-412.

Corrales Zumbado, Cristóbal y Dolores Corbella Díaz. 2012. "La aportación del portugués a la formación de la terminología azucarera". Anuario de estudios atlánticos 58: 705-754.

Corrales Zumbado, Cristóbal, Dolores Corbella Díaz y Ana Viña. 2015. Léxico azucarero atlántico (siglos XVI-XVII). San Millán de la Cogolla: Cilengua y Fundación San Millán de la Cogolla.

Corriente, Federico. 1996. "Los arabismos del portugués". Estudios de dialectología norteafricana y andalusí 1: 5-86. 2000. "Los arabismos del español de Canarias". Estudios Canarios 45: 187-203.

.2008a. Romania Arabica. Tres cuestiones básicas: Arabismos, "mozárabe” y "jarchas". Madrid: Trotta.

2008b. "Vigencia del romandalusí y su documentación en los botánicos, particularmente Abulhayr". ¿Existe una identidad mozárabe?: historia, lengua y cultura de los cristianos de al-Andalus (siglos IX-XII). Collection de la Casa de Velázquez Vol. 101. Eds. Cyrille Aillet, Mayte Penelas y Philippe Roisse. Casa de Vélazquez. 83-89.

. 2011. "A vueltas con los arabismos del español de Canarias". Estudios Canarios 55: 365-389.

2012. "Arabismos lusismos del español de Canarias". En Lexicografia hispánica del S. XXI. Nuevos proyectos y perspectivas. Homenaje al Profesor Cristóbal Corrales Zumbado. Madrid: Arco Libros. 211-218.

2013. "Los arabismos y otras voces medio-orientales del Dicionário Houaiss da Lingua Portuguesa". Filologia e Linguística Portuguesa 15: 69-184.

DA = Asociación de Academias de la Lengua Española. 2010. Diccionario de Americanismos. Madrid: Santillana. Versión digital: http://lema.rae.es/damer/?key=

DAAL $=$ Corriente, Federico. 2008. Dictionary of Arabic and Allied Loanwords: Spanish, Portuguese, Catalan, Galician and Kindred Dialects. Handbook of Oriental Studies vol. 97. Leiden: Brill.

DAI = Corriente, Federico. 2003. Diccionario de arabismos y voces afines en iberorromance. Biblioteca Románica Hispánica vol. 22. Madrid: Gredos.

DEC $=$ Corrales, Cristóbal y Corbella, Dolores. 2009. Diccionario ejemplificado de canarismos. La Laguna: Instituto de Estudios Canarios.

DCECH = Corominas, Joan y Pascual, José A. Diccionario crítico y etimológico castellano e hispánico. 6 vols. 1983-91. 5 reimpr. Madrid: Gredos.

DDEC $=$ Corrales Zumbado, Cristóbal, Dolores Corbella Díaz y Ma Ángeles Álvarez. 1996. Diccionario diferencial del español de Canarias. Madrid: Arco Libros.

DHECan = Corrales Zumbado, Cristóbal y Dolores Corbella Díaz. 2001. Diccionario histórico del español de Canarias . La Laguna: Instituto de Estudios Canarios [2013]. 2 edición ampliada, versión digital: http://web.frl.es/DHECan.html

DRAE 2014 = Real Academia Española. Diccionario de la lengua española. $23^{\mathrm{a}}$ ed. Madrid: Espasa.

Dworkin, Steven N. 2008. "Towards a Typology of Lexical Borrowing: Primary Adjectives as Loanwords in Spanish". Lenguas en diálogo: el iberorromance y su diversidad lingüistica y literaria: ensayos en homenaje a Georg Bossong. Eds. Hans-Jörgen Döhla, Raquel Montero Muñoz y Francisco Báez de Aguilar González. Madrid: Iberoamericana; Frankfurt: Vervuert. 111-123.

Fasla Fernández, Dalila 1998-99. "Aportaciones terminológicas de la lengua árabe al español medieval, moderno y contemporáneo notas para un análisis etnolingüístico y reflexiones críticas”. RESLA 13: 243-259. 
2007-2008. "El español hablado en Cuba: préstamos vigentes, lexicogénesis y variación lingüística". Cuadernos de investigación filológica 33-34: 73-96.

2010. "Préstamos léxicos vigentes en el español hablado en Cuba: Productividad morfosemántica e implicaciones socio-culturales". Actas del XVI Congreso de la Asociación Internacional de Hispanistas: Nuevos caminos del hispanismo. Eds. Pierre Civil y Françoise Crémoux. Vol. 2 [CD-ROM]. Madrid: Iberoamericana; Frankfurt am Main: Vervuert. [133-142].

Fasla Fernández, Dalila y Alain Concepción. 2000. "El léxico de origen árabe en el español de las dos orillas: anotaciones diacrónicas, diatópicas y sociolectales". Anuario de Estudios Filológicos 23:103-122.

Fernández-Sevilla, Julio. 1975. Formas y estructuras en el léxico agrícola andaluz: interpretación y estudio de 200 mapas lingüisticos. Vol. 1. Consejo Superior de Investigaciones Científicas.

Frago García, Juan Antonio. 2004. Andaluz y español de América: historia de un parentesco lingüistico. Sevilla: Junta de Andalucía. Consejería de Cultura y Medio Ambiente.

Galmés de Fuentes, Álvaro 1996. Influencias sintácticas y estilisticas del árabe en la prosa medieval castellana. Madrid: Gredos.

1999-2000. Romania Arabica: estudios de literatura comparada árabe y romance. I y II. Madrid: Real Academia de la Historia.

García González, Javier. 2007. "Una perspectiva sociolingüística de los arabismos en el español de la Alta Edad Media 711-1300”. Ex admiratione et amicitia. Homenaje a Ramón Santiago. Coords. Alicia Puigvert Ocal e Inmaculada Delgado Cobos. Madrid: Ediciones Clásicas. 523-548.

2008. "Cuestiones pendientes en el estudio de los arabismos del español medieval: una nueva revisión crítica”. Lenguas, reinos y dialectos en la Edad Media Ibérica. La construcción de la identidad. Homenaje a Juan Ramón Lodares. Eds. Javier Elvira, Inés Fernández-Ordóñez et al. Madrid: Iberoamericana; Frankfurt: Vervuert. 257-286.

García Mouton, Pilar. 2009. "La investigación geolingüística española en la actualidad". La investigación dialectológica en la actualidad. Eds. Dolores Corbella y Josefa Dorta. Santa Cruz de Tenerife: Agencia Canaria de Investigación, Innovación y Sociedad de la Información del Gobierno de Canarias. 333-346.

García Mouton, Pilar, David Heap y Maria-Pilar Perea. 2012. "The present and the future of the Atlas Lingüistico de la Peninsula Ibérica ALPF". Dialectologia III: 1-6.

Garulo Muñoz, Teresa. 1983. Los arabismos en el léxico andaluz. Madrid: Instituto Hispano-Árabe de Cultura.

Glessgen, Martin-Dietrich. 1996. Die Falkenheilkunde des "Moamin" im Spiegel ihrer volgarizzamenti: Studien zur Romania Arabica. Tübingen: Max Niemeyer Verlag.

Haensch, Günther. 1997. Los diccionarios del español en el umbral del siglo XXI. $1^{\text {a }}$ ed. Salamanca: Universidad de Salamanca.

Haugen, Einar. 1950. "The Analysis of Linguistic Borrowing”. Language 26.2: 210-231.

Herrera del Castillo, Ma Teresa. 1996. "Algunos datos sobre la interrelación léxica entre el portugués y el español en las Islas Canarias". Actas del Congreso Internacional luso-español de la lengua y cultura en la frontera: Cáceres, 1 al 3 de diciembre de 1994. Coords. Juan María Carrasco González y A. Viudas Camarasa. Cáceres: Universidad de Extremadura, Servicio de Publicaciones. Vol I. 519-528.

Haspelmath, Martin. 2008. "Loanword typology: Steps toward a systematic cross-linguistic study of lexical borrowability." Aspects of Language Contact: New Theoretical, Methodological and Empirical Findings with Special Focus on Romancisation Processes. Empirical Approaches to Language Typology [EALT] vol. 35. Eds. Thomas Stolz, Dik Bakker y Rosa Salas Palomo. Berlin: De Gruyter Mouton. 43-62.

2009. "Lexical borrowing: Concepts and issues". Loanwords in the world's languages: A comparative handbook. Eds. Martin Haspelmath y Uri Tadmor. Berlin: De Gruyter Mouton. 35-54.

Kiesler, Reinhard. 1993. "La tipología de los préstamos lingüísticos: no sólo un problema de terminología". Zeitschrift für Romanische Philologie 109: 505-525.

KVWAI = Kiesler, Reinhard. 1994. Kleines vergleichendes Wörterbuch der Arabismen im iberoromanischen und Italienischen. Tübingen: Francke.

López Serena, Araceli. 2013. "La heterogeneidad interna del español meridional o atlántico: variación diasistemática vs. pluricentrismo". Lexis XXXVII.1: 95-161.

Lüdtke, Jens. 1996. "Das indianische Fremde als arabisches Fremdes". En Romania Arabica. Festschrift für Reinhold Kontzi zum 70. Geburtstag. Tübingen: Gunter Narr Verlag. 481-493.

2004. "Las perspectivas etnolingüísticas en el léxico novohispano del S. XVI". Historia del léxico español. Enfoques y aplicaciones. Eds. Jens Lüdtke y Christian Schmitt. Lingüística Iberoamericana vol. 21. Madrid: Iberoamericana; Frankfurt: Vervuert. 285-302.

2014. Los origenes de la lengua española en América. Los primeros cambios en las Islas Canarias, las Antillas y Castilla del Oro. Lingüística Iberoamericana vol. 54. Madrid: Iberoamericana; Frankfurt: Vervuert.

Llorente Maldonado de Guevara, Antonio. 1987. El léxico del tomo I del "Atlas Lingüistico y etnográfico de las Islas Canarias". Cáceres: Universidad de Extremadura.

Maíllo Salgado, Felipe. 1998. Los arabismos del castellano en la Baja Edad Media. Salamanca: Ediciones Universidad de Salamanca.

Maranhão, Samantha. 2012. "A Língua Portuguesa e a Romania Arabica”. Ciências \& Letras [Porto Alegre] 51 jan./jun.: 
157-179.

Martinell Grifé, Emma y Mar Cruz Piñol, eds. 1996. La conciencia lingüistica en Europa. Testimonios de situaciones de convivencia de lenguas SS. XII-XVIII. Barcelona: Editorial PPU.

Medina López, Javier. 2013. "La formación lingüística de Canarias: sustratos, contactos e historia. Un balance de cinco siglos". Zeitschrift für Romanische Philologie 129: 413-445.

Morala Rodríguez, José Ramón y Le Men Loyer, Jeannick. 2007. "Sobre algunos occidentalismos en el español de América". El español de América. Actas del VI Congreso Internacional de "El español de América" (Tordesillas, Valladolid, 25-29 de octubre 2005). Eds. César Hernández Alonso y Leticia Castañeda San Cirilo. Valladolid: Diputación de Valladolid. 641-650.

Morera Pérez, Marcial. 2009. "La evolución lingüística de Canarias. Del multilingüismo de los siglos XV y XVI al monolingüismo actual. Esbozo del problema”. Letras de Deusto 39.125: 125-163.

Morgenthaler García, Laura. 2008. Identidad y pluricentrismo lingüistico. Hablantes canarios frente a la estandarización. Lengua y sociedad en el mundo hispánico vol. 19. Madrid: Iberoamericana; Frankfurt: Vervuert.

Narbona Jiménez, Antonio, Rafael Cano Aguilar y Ramón Morillo-Velarde Pérez. 2011. El español hablado en Andalucía. Sevilla: Universidad de Sevilla.

Nunes Nunes, Naidea. 2003. Palavras Doces. Terminologia e tecnología históricas e actuais da cultura açucareira. Funchal: Centro de Estudos de História do Atlântico.

Pérez Vidal, José. 1991. Los portugueses en Canarias. Portuguesismos. Las Palmas de Gran Canaria: Cabildo Insular de Gran Canaria.

Ross, Malcolm. 1991. "Refining Guy's sociolinguistic types of language change". Diachronica 8.1: 119-29.

Serrano-Niza, Dolores. 2007. "Arabismos relacionados con el léxico de la seda”. Revista de Filología 25: 559-566.

Steiger, Arnald. 1991. Contribución a la fonética del hispano-árabe y de los arabismos en el ibero-románico y el siciliano. Madrid: CSIC

TLEC $=$ Corrales, Cristóbal, Dolores Corbella y Ma Ángeles Álvarez. 1992. Tesoro lexicográfico del español de Canarias. $2^{\mathrm{a}}$ ed. Madrid: RAE; Canarias: Consejería de Educación, Cultura y Deportes del Gobierno de Canarias.

Tadmor, Uri. 2009. "Loanwords in the world's languages: findings and results". Loanwords in the World's Languages: A Comparative Handbook. Eds. Martin Haspelmath y Uri Tadmor. Berlin: Walter de Gruyter. 55-75.

Thomason, Sarah G. y Kaufman, Terrence. 1988. Language Contact, Creolization and Genetic Linguistics. Berkeley: U. of California Press.

Versteegh, Kees. 2001. "Linguistic contacts between Arabic and other languages". Arabica XLVIII: 470-508.

Vidal-Luengo, A. R. y Cáceres- Lorenzo, M. T. 2014. "Arabismos en el español atlántico". 6th International Conference on Corpus Linguistics. Las Palmas de Gran Canaria, 22-24 mayo 2014. DOI: 10.13140/2.1.3260.1285. 